\title{
Acute myocarditis as simulator of an acute myocardial infarction
}

\author{
Miocarditis aguda como simuladora de infarto con ST elevado \\ Gabriela Santamaría-Naranjo* and Nelson E. Amores-Arellano \\ Department of Cardiology, Hospital Carlos Andrade Marín. Quito, Ecuador
}

Myocarditis is an inflammatory disease of the myocardium and one of the main causes of dilated cardiomyopathy, heart failure, and sudden death. An incidence of $22 / 100,000$ population is estimated, that is, 1.5 million cases in the world population (2013 $)$, and it accounts for $5-22 \%$ of sudden cardiac deaths in young individuals ${ }^{2}$.

For its definition and diagnosis, there are clinical, histopathological, and immune criteria. The histopathological findings described by Dallas define it as the presence of inflammatory infiltrates in the myocardium, associated with myocyte degeneration and necrosis of non-ischemic cause. In addition, some immunohistochemical criteria have been formulated: presence of at least 14 leukocytes $/ \mathrm{mm}^{2}$ in the myocardium, including up to 4 monocytes $/ \mathrm{mm}^{2}$, and detection of 7 or more CD3-positive T-lymphocytes ${ }^{3}$.

The most common causes are viral (particularly enteroviruses), bacterial, fungal, and parasitic infections. Non-infectious causes have also been described, including autoimmune diseases, drug hypersensitivity, and toxins ${ }^{3}$.

Its clinical presentation is variable, ranging from barely symptomatic patients to a clinical profile that resembles acute coronary syndromes or electrical disorders, and even cases that develop acute heart failure and cardiogenic shock have been described; this makes early diagnosis difficult, and electrocardiographic and imaging studies are, therefore, vitally important for diagnosis.

The case of a 39-year-old male patient with a history of cocaine and marijuana use is presented here, who consulted for angina at rest. He was initially evaluated in a secondary care center, after having experienced symptoms for $6 \mathrm{~h}$; the electrocardiogram (ECG) (Fig. 1) showed anterior ST-elevation, and ST-segment elevation myocardial infarction was therefore established; fibrinolytic treatment was started without changes in ECG tracing or pain relief being achieved. He was transferred immediately to the authors' center for rescue percutaneous coronary intervention. Coronary angiography showed healthy coronary arteries with TIMI 3 flow.

Initial echocardiographic evaluation showed lateral and inferolateral hypokinesia, left ventricular ejection fraction of $58 \%$ and G2 diastolic dysfunction. The troponin curve showed an increasing behavior with up to $300 \mathrm{~N}$ values.

With this evidence, a contrasted cardiac magnetic resonance imaging (MRI) was performed (Fig. 2), which showed areas of edema and delayed intra-myocardial enhancement at the lower and lateral areas, which was consistent with myocarditis. Based on this diagnosis, vasodilator treatment was started with angiotensin-converting enzyme inhibitor and beta-blocker, with favorable clinical response.

\section{Correspondence:}

*Gabriela Santamaría-Naranjo

E-mail: gabricsantamaria@gmail.com DOI: 10.24875/ACME.M20000136 license (http://creativecommons.org/licenses/by-nc-nd/4.0/).
Available online: 04-12-2020 Arch Cardiol Mex (Eng). 2020;90(3):322-324 www.archivoscardiologia.com
n open access article under the CC BY-NC-ND 


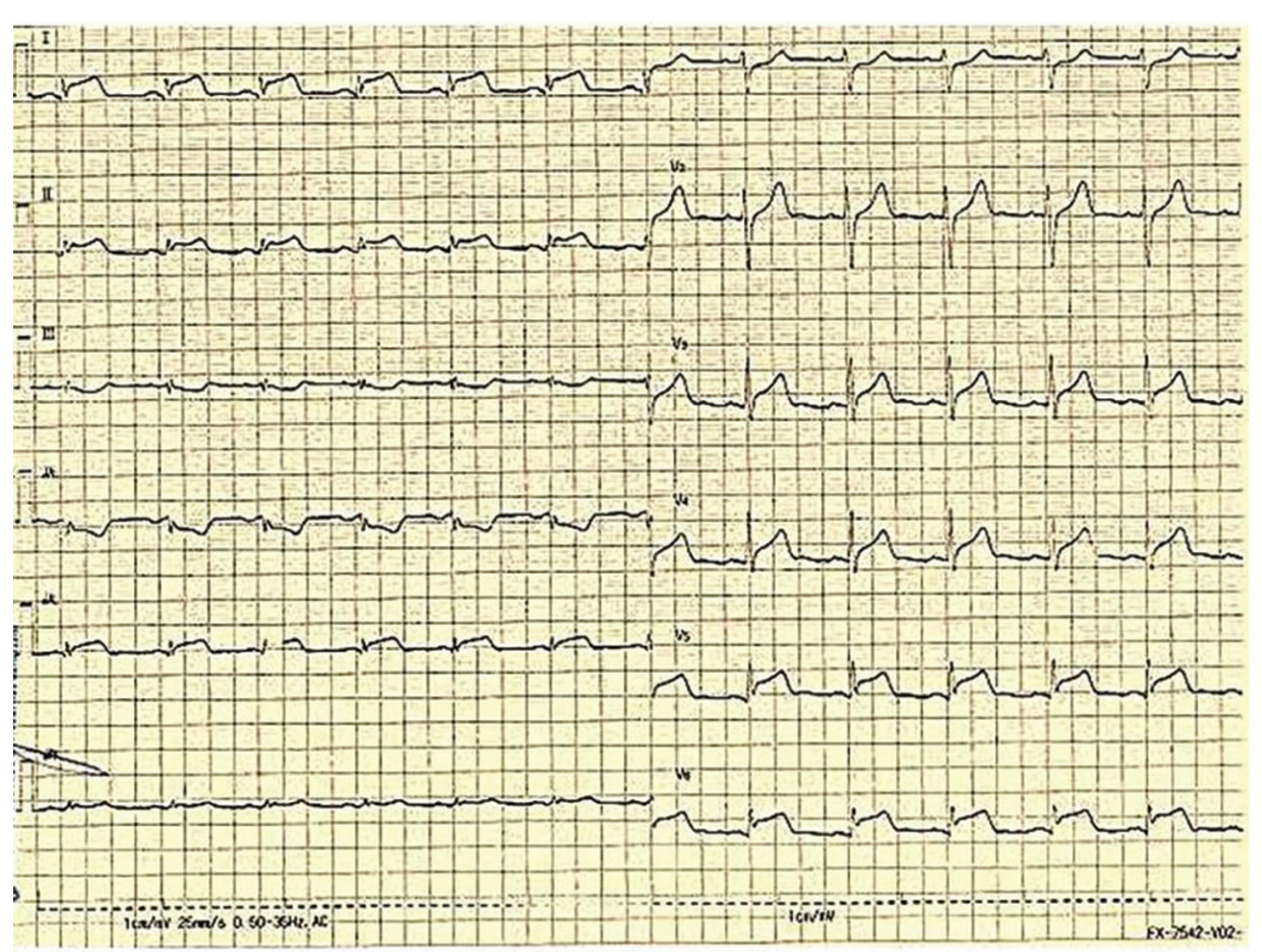

Figure 1. 12-lead electrocardiogram.

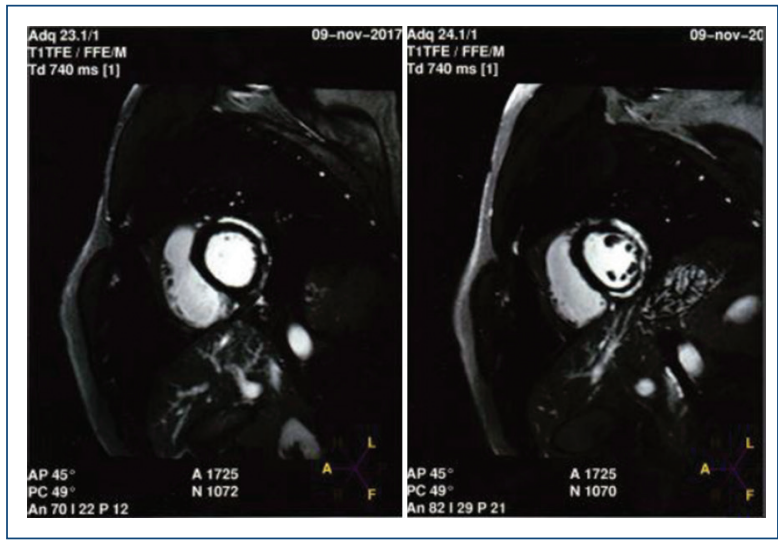

Figure 2. Cardiac magnetic resonance imaging with delayed gadolinium enhancement.

Follow-up for 1 year was established, and the patient is currently asymptomatic, with echocardiographic evaluation showing a left ventricle without motility disorders, ejection fraction of $64 \%$, and normal diastolic function.

Myocarditis can mimic an acute myocardial infarction by its clinical presentation, electrocardiographic findings, and mobilization of myocardial cytolysis markers. In a study of 45 patients with suspected acute coronary syndrome and a normal coronary angiogram, 35 (78\%) had imaging-confirmed diffuse or focal myocarditis ${ }^{4}$.

Echocardiographic findings include diffuse or regional motility disorders, systolic dysfunction, and changes in the left ventricle geometry, which are also common in acute ischemia.

Cardiac MRI (CMR) has become the imaging method of choice for the diagnosis of myocarditis, given that it offers morphological and functional information, as well as tissue characterization in a non-invasive way. The findings acquire greater sensitivity from the $7^{\text {th }}$ day of disease evolution onward.

Cardiovascular MRI can detect edema as T2-increased intensity, a finding that can be focal or diffuse. Hyperemia is shown as T1-increased early gadolinium uptake; and myocardial necrosis and fibrosis create a delayed enhancement pattern in patches without respecting the vascular territory, which alters the sub-epicardium without modifying the sub-endocardium. These characteristics allow differentiation with ischemic involvement. Diagnostic confirmation by cardiovascular MRI is carried out 
using the Lake and Louise criteria, and it is positive when at least two of the following are observed:

1. Focal or diffuse signal increase in T2-weighted sequences.

2. Early gadolinium enhancement after determining total absolute or relative myocardial enhancement.

3. At least one focal, non-ischemic delayed enhancement focus ${ }^{5}$.

The presence of two of the three criteria offers a diagnostic accuracy of $78 \% \%^{5}$. Myocarditis control is based on the vasodilator treatment administration, depending on the degree of left ventricular systolic dysfunction. Individuals with cardiogenic shock, high-grade atrioventricular block, sustained ventricular arrhythmias, and treatment failure after the first 2 weeks require endomyocardial biopsy to establish positivity for viral markers and specifically determine the treatment ${ }^{6}$.

All patients diagnosed with myocarditis should have physical activity restricted for 6 months, and reintegration to exercise occurs only after echocardiographic evaluation confirms left ventricular normal function.

CMR is perhaps the best imaging method to control myocardial damage evolution, but there were no clear data on its prognostic significance in the follow-up of myocarditis-diagnosed patients until the ITAMY (ITAlian study in MYocarditis) study ${ }^{7}$, which included a total of 187 patients with suspected myocarditis and preserved systolic function undergoing CMR during the acute phase and then a control CMR at 6 months, whereby more specifically establishing its evolution and risks was possible.

During follow-up, patients in whom delayed enhancement increased in the second CMR were found to develop significantly more cardiac episodes (death from cardiac cause, recovered cardiac arrest, transplantation, ventricular assistance, implantable automated cardioverter defibrillator appropriate discharge, and hospitalization for heart failure); similarly, patients who had delayed enhancement without edema showed poorer outcomes than those in whom it persisted. All of the above leads to recommend CMR at 6 months as a study for follow-up in these cases.

Finally, the prognosis of patients with acute myocarditis varies depending of the clinical scenario and the degree of left ventricular dysfunction, and it can evolve into multiple entities, such as chronic myocarditis, myopericarditis, as well as a serious complication, normal or dilated inflammatory cardiomyopathy, which is characterized by a dilated left ventricle with systolic dysfunction.

\section{Funding}

This research has not received any specific grant from agencies of the public, commercial, or non-profit sectors.

\section{Conflict of interests}

None.

\section{Ethical disclosures}

Protection of human and animal subjects. The authors declare that no experiments were performed on humans or animals for this research.

Confidentiality of data. The authors declare that they have followed the protocols of their work center on the publication of patient data.

Right to privacy and informed consent. The authors have obtained informed consent from the patients or subjects referred to in the article.

\section{References}

1. Global Burden of Disease Study 2013 Collaborators T, Barber RM, Bell B, Bertozzi-Villa A, Biryukov S, Bolliger I, et al. Global, regional, and national incidence, prevalence, and years lived with disability for 301 acute and chronic diseases and injuries in 188 countries, 1990-2013: a systematic analysis for the Global Burden of Disease Study 2013. Lancet (London, England) [Internet]. 2015 Aug 22 [cited 2018 Sep 12];386(9995):743-800. Available from: http://www.ncbi.nlm.nih.gov/pub$\mathrm{med} / 26063472$

2. Shah N, Phelan DMJ. Myocarditis in the athlete - American College of Cardiology [Internet]. 2018 [cited 2018 Sep 12]. Available from: https:// www.acc.org/latest-in-cardiology/articles/2018/01/18/15/00/myocardi-tisin-the-athlete

3. Domínguez F, Kühl U, Pieske B, García-Pavía P, Tschöpe C. Actualiza-ción sobre miocarditis y miocardiopatía inflamatoria: el resurgir de la biopsia endomiocárdica. Rev Esp Cardiol. 2016;69(2):178-187; Available from: http://dx.doi.org/10.1016/j.recesp.2015.10.018 0300-8932/2015 So-ciedad Española de Cardiología. Publicado por Elsevier España, S.L.U. Todos los derechos reservados

4. Cooper LT. Clinical manifestations and diagnosis of myocarditis in adults - UpToDate. 2018 [cited 2018 Sep 12]; Available from: https://www.uptodate.com/contents/clinical-manifestations-and-diagnosis-of-myocar-ditis-in-adults/print

5. De Castro ABG, Martínez BC, Domínguez JF, Villafañe CG, Fernán-dez-Golfín C. Miocarditis: diagnóstico y seguimiento con resonancia magnética. Radiología. 2013;55(4):294-304

6. Yic C, Pontet J, Cancela M. Miocarditis fulminante, caso clínico. Rev Méd Urug 2015;31(1):53-57.

7. Donato G. Prognostic value of repeating cardiac magnetic resonance in patients with acute myocarditis, J Am Coll Cardiol. 2019;74(20):24392448. 